\title{
JOVEM RURAL EM QUESTÃO
}

\section{RURAL YOUTH IN QUESTION}

\author{
EZEQUiel REDIN ${ }^{1}$
}

Recebido em: 16/04/2011

Aprovado em: 10/11/2011

\section{RESUMO}

O trabalho tem por objetivo compreender as relações estabelecidas pelos jovens rurais, mediados por aspectos de trabalho e de sociabilidade, relacionando-os com as formas de organização social local. Para tanto, intercalam-se reflexões analíticas apoiadas em referências bibliográficas, contrastando com o caso da Associação da Juventude Rural de Arroio do Tigre (AJURATI). A constituição histórica da associação propõe romper com a invisibilidade do jovem, constituindo-os em processos de valorização, legitimação e reconhecimento social. A análise baseia-se em desconstituir a concepção de intervenção voltada apenas para os componentes trabalho e produção, atentando para estímulos e incentivos de políticas voltadas para sociabilidade, lazer, entretenimento, educação e cultura. $\mathrm{O}$ estudo demonstra a necessidade de um re-olhar para o jovem rural, através de uma experiência estimulada na década de 80 , pela atuação da extensão rural, que se transformou em relevante espaço na sociedade local, protagonizado pelo potencial de transformação do jovem rural.

Palavras-chave: Jovens rurais; Trabalho; Sociabilidade; Reconhecimento; AJURATI .

\section{Introdução}

Este artigo, como qualquer outro, tem sua retrospectiva, não sendo, portanto uma análise desligada das relações do rural. É nesse contexto, que se apresenta a realidade dos jovens rurais do município de Arroio do Tigre, que, por fatos, mostra-se particularmente uma apreciação um pouco distinta do que vem se apresentando na literatura,

\begin{abstract}
The study aims to understand the relationships established by rural youth, mediated by aspects of work and sociability, linking them with the forms of local social organization. To this end, merges reflections are supported by analytical references, contrasting with the case of rural youth of Arroio do Tigre (AJURATI). The historical constitution of the association proposes to break with the invisibility of the young, being in recovery processes, legitimacy and social recognition. The analysis is based on deconstruct the design of intervention directed only to the components work and production, focusing on encouragement and incentive policies for sociability, recreation, entertainment, education and culture. The study demonstrates the need for an other look at the rural youth through a stimulating experience in the 80's, by the performance of extension, which became a important space in local society played by transformative potential of rural youth.

Keywords: Rural youth; Work; Social life; Recognition; AJURATI.
\end{abstract}

sobre a questão do jovem rural. A partitura do assunto já foi tema de discussões anteriores sobre a juventude rural de Arroio do Tigre, sobretudo, como suas ações interferem no comportamento e na auto-identificação do jovem rural (ver Rauber et al., 2008; Redin et al., 2009).

Em âmbito geral, o foco das publicações adverte para a pesquisa em torno da temática como problema so-

\footnotetext{
${ }^{1}$ Doutorando em Extensão Rural pela Universidade Federal de Santa Maria. Editor do Periódico Extensão Rural - Série de Estudos Rurais. Tutor a distância do Tecnólogo em Agricultura Familiar e Sustentabilidade. 
cial, enfatizando o possível esvaziamento do campo, o inchamento dos centros urbanos (Abramovay e Camarano, 1997) e a disparidade em termos de educação, renda e qualidade de vida. No entanto, ainda carece, na literatura, um estudo demográfico consistente, que mensure a diferença do êxodo, da migração, da circulação e da migração sazonal, como aponta Castro. A autora ainda enfatiza que a juventude rural teve uma atenção modesta diante da juventude urbana, comentando sobre as pesquisas na área, na última metade do século (CASTRO, 2005).

A juventude rural é compreendida aqui como construção social, conforme sugere Bourdieu (1984, p. 152), “(...) a juventude e a velhice não são dadas, mas construídas socialmente, na luta entre jovens e velhos. A relação entre idade social e idade biológica é muito complexa". Desse modo, rompe-se, nesta análise, a delimitação do fator idade, constituindo-se um segmento que transforma lutas e esforços em prol da continuidade do jovem nas suas formas associativas, com tratamento especial para a sociabilidade no espaço rural, em diversas formas de lazer, convívio, entretenimento e troca de experiências, tanto as pessoais quanto àquelas relativas a técnicas produtivas. Em outras palavras, espaços de aprendizagem de conhecimento informais e cotidianos. Nessa concepção, entende-se aqui que juventude rural é um grupo de jovens rurais que se organiza em prol de um objetivo específico - lazer, trabalho, esporte ou cultura. Em anterior trabalho sobre essa organização social, o jovem rural foi definido em Redin et al., como: "ser jovem rural é participar das atividades tanto esportivas, culturais ou sociais com orgulho, compromisso e espírito de união em prol do bem comum, independente de estado civil, idade ou outro condicionante físico" (2009, p.124).

Juventude rural é um tema contemporâneo na imersão das discussões que envolvem a agricultura familiar, a sucessão da terra, o desenvolvimento rural, a segurança alimentar, a reprodução social da família, as futuras interações e estratégias de desenvolvimento. Enfim, a essa categoria é posta uma responsabilidade imensa sob as perspectivas vindouras do espaço rural. Contrapondo a isso, percebe-se um status construído na sociedade urbana, em que existe a possibilidade de oferecer, ao jovem, um mundo idealizado, um imaginário social, voltado a padrões de ocidentalização de atitudes e comportamentos. Pensando desse modo, que o jovem rural se propõe a buscar, na sociedade urbana, seu espaço; contudo, muitas vezes, volta ao rural frustrado por não desfrutar de todos aqueles bens e serviços tão midiatizados nos meios de comunicação. Nessa breve afirmação, não se pretende assegurar que todos os casos conhecidos tenham como produto final a "volta ao rural". Muito pelo contrário, têm-se inúmeros exemplos de jovens que saíram do campo e que tiveram uma trajetória de luta e de sucesso no meio urbano, enquanto outros nem tanto, apesar de que também não tiveram a possibilidade de voltar.

As publicações sobre os jovens rurais acresceram-se na última década, incorporando analistas como Abramovay et al., (1998), Carneiro, (1998), Silvestro et al., (2001), Castro (2005), Stropasolas (2006), Brumer e Spanevello (2008), Marin (2009) e outros. Por outro lado, as políticas públicas sociais voltadas ao gênero, apesar da evolução, ainda não conseguiram resultados expressivos. Em certos momentos, as escolhas dos jovens rurais não estão ligadas a inexistência de intervenções rurais ou de baixa renda, mas vinculadas a projetos de vida, ou sonhos, além do meio rural, ou que, talvez, o rural ainda não proporcione, como por exemplo, a educação superior presencial.

Contracenar com a valorização do jovem no campo é, antes de tudo, fornecer condições materiais, espaços de sociabilidade, possibilidade de continuar os estudos sem necessitar migrar 
para grandes centros urbanos, dar subsídios ao produto do trabalho na agricultura familiar, proporcionar formas de amenizar o isolamento cultural, político e social, bem como aumentar o leque de alternativas de desenvolvimento. A premissa fundamental é, portanto, assegurar condições que possibilitem, ao jovem rural, munir qualidade de vida aliada aos projetos individuais ou aos coletivos, no rural.

Os problemas da agricultura provocam frustrações nas famílias agricultoras, principalmente, como apontam Pinheiro e Carvalho (2003), pelos baixos rendimentos da atividade agrícola, pela variabilidade dos preços e das produções, pelos problemas estruturais e pela dilapidação dos recursos naturais. Essa constatação provoca um sentimento de frustração com a atividade, levando a família influenciar os filhos a procurarem outras formas de reprodução, geralmente, atividades não agrícolas, tentando amenizar o sofrimento, ou ainda, oportunizar, na concepção dos atores rurais, maneiras de reprodução social com menores riscos embutidos.

Este trabalho tem por objetivo compreender as relações estabelecidas pelos jovens rurais, mediados por aspectos de trabalho e de sociabilidade, relacionando-as com as formas de organização social local. Posteriormente, se utilizará de uma experiência para analisar as formas associativas dos jovens rurais, oportunizando espaços de sociabilidade, valorização e reconhecimento local.

\section{O jovem rural e suas implicações "invisíveis"}

O debate do jovem no meio rural, em boa parte dos casos, está relacionado com a sua invisibilidade perante a sociedade. Castro (2009, p.182) ressalta que "a própria imagem de um jovem desinteressado pelo meio rural contribui para a invisibilidade da categoria como formadora de identidades sociais e, portanto, de demandas sociais". Para rom- per com a invisibilidade da categoria, é necessário acreditar que as formas de representação dos jovens rurais possam trazer novas concepções em torno das problemáticas atuais, tratando de valorizar o espírito inovador diante das dificuldades econômicas e sociais do rural.

Entender o processo migratório dos jovens rurais é altamente subjetivo e impede generalizações de realidades específicas. Essa situação mostra uma gama de particularidades, racionalidades, interesses e motivações, que movimentam o contexto em que se inserem, refletindo exatamente no meio urbano. Como já argumentava Cassol em 1984, a fixação do homem rural é algo importante e imperioso, que não se faz por meio de portarias ou mesmo decretos, é preciso uma ação conjunta entre poderes e tecnologia, apoiados na firmeza estrutural (CASSOL, 1984).

A questão, além de ser complexa, pede o apoio estatal, uma vez que se trata de uma categoria promissora. Outrora, se não se disponibilizam meios para que haja uma condição de igualdade e de oportunidades entre jovens rurais e urbanos, a necessidade de sair do campo se torna cada vez maior. A juventude rural, em alguns locais, aparece como uma classe extremamente fragilizada da sociedade. Em várias realidades, a juventude rural passa despercebida, sem motivações, anseios ou credibilidade da comunidade, por serem ainda considerados como incapazes de se reproduzir. Existe certo consenso, entre os pesquisadores, de que o jovem é posto em segundo plano, nas formulações de estratégias de desenvolvimento, sequer então, falar sobre o descaso do jovem rural na agricultura familiar.

Com base nessas considerações, o Programa Nacional de Fortalecimento da Agricultura Familiar (PRONAF), criado em 1996, tem com objetivo fortalecer a agricultura familiar e contribuir na geração de empregos e renda nas áreas rurais e urbanas, intencionando melhorar a qualidade de vida dos produtores 
familiares. Dentre as inúmeras linhas do Pronaf (Custeio, Investimento, Agroindústria, Agroecologia, Eco, Floresta, Semiárido, Mulher, Jovem, Custeio e Comercialização de Agroindústrias Familiares, Cota-Parte, Microcrédito Rural e Mais Alimentos), destaca-se a linha especifica do jovem. Grosso modo, o crédito não é o único problema da migração dos jovens rurais para os centros urbanos, como já se destacou. De certa forma, o Pronaf é um programa amplo, que não delega objetivos específicos que atentam para os jovens rurais. Corroborando, então, com a afirmação de Castro (2009, p. 183): " juventude rural também não se apresenta como foco prioritário para as políticas públicas de juventude".

A inexistência de ações de intervenção para a juventude rural no Brasil acarreta na exclusão social, como expressa Castro (2009, p. 195), “(...) seja pela invisibilidade de suas demandas nas esferas das políticas públicas, (...), seja pelas difíceis condições de permanência dos jovens no meio rural, afetada por questões 'objetivas' e 'subjetivas', 'novas' e 'velhas". Concordando com essa reflexão, Rua (1998) afirma que, até existir uma inclusão mais efetiva, ter-se-á uma situação mais ou menos prolongada de incômodo, de injustiça, de insatisfação ou de perigo, que alcança a categoria dos jovens rurais, sem chegar a compor a agenda governamental ou a mobilizar as autoridades políticas.

A criação de estratégias requer anular a invisibilidade que caracteriza os jovens na agricultura, pois a juventude é invisível para muitos projetos de combate à pobreza rural, é invisível para as organizações que tratam do tema no setor urbano e, ainda, é invisível aos próprios sociólogos que, em suas pesquisas sobre os jovens, esquecem que existe uma juventude rural, segundo Durston (1999).

Outros analistas, como Carneiro (1998), afirmam que os jovens rurais, ou filhos de agricultores, ficam preenchendo o vazio estatístico composto pelos que ainda não ingressaram na vida ativa, esperando atingir a maioridade para se tornarem visíveis à sociedade. E nessa perspectiva negativa que Rodríguez (1993) chama a atenção para a quantidade e a qualidade dos serviços públicos que estão acessíveis em cada caso, haja vista que foram paulatinamente se reduzindo, ao longo das últimas décadas, o que conduziu a que os jovens rurais tenham, hoje, como se sabe, menos educação, renda mais baixa, menos treinamento e mais oportunidades limitadas para desenvolvimento pessoal e social futuro, que os jovens urbanos.

A categoria ainda sofre os reflexos do difícil acesso, da falta de presença física, da pressão nas camadas sociais, do paternalismo da própria família. Pois é isso que parece facilitar sua invisibilidade na comunidade e nas políticas públicas. É nessa perspectiva que Reuben (1990) revela que a invisibilidade é um dos principais fatores que inibem o desenvolvimento das potencialidades dos jovens, o que os impede de contribuir para o desenvolvimento rural sustentável. Uma das barreiras é de ordem cultural e está associada aos conflitos dos jovens na família. $\mathrm{O}$ jovem não consegue ser ouvido em seu ambiente familiar. A estrutura patriarcal ainda existente na maioria das áreas rurais, limita o acesso dos jovens a manifestações e, até mesmo, na tomada de decisões.

Existe um consenso, na base analítico-teórica, que a inexistência de intervenção estatal, sob o âmbito de políticas públicas, agrava os problemas com a juventude rural, conforme Abramovay (1998), Rodríguez (1993), Castro (2009), Rua (1998), Durston (1999), Carneiro (1998), Cassol (1984), entre outros. Como consequência, condiciona-se, de certo modo, a saída do campo, caracterizando o processo migratório. Evidentemente, é necessária, relevante e fundamental a formulação e a aplicação de políticas mais específicas para a permanência dos jovens rurais, con- 
tudo, independente desta, acredita-se que é necessário algo mais para a sua permanência. Por outro lado, a invisibilidade teórica já começa a ficar suprimida pelas pesquisas nacionais apontadas na última década, ou, pelo menos, já se tem um singelo avanço. A invisibilidade ao Estado, por sua vez, necessitará de um progresso muito mais dispendioso, significativo e relevante, do que vem ocorrendo, apesar de constatar uma evolução nos últimos anos.

É necessário, além de tudo, um processo de reconhecimento do jovem rural pela sociedade urbana, e não um prestígio inócuo. Reverter o quadro de desvalorização, de invisibilidade e, acima de tudo, proporcionar, ao rural, as mesmas condições de acesso a bens e a serviços promovidos no meio urbano já se mostra um grande avanço. Necessariamente, ainda se tem um enorme caminho a trilhar.

\section{Para além do trabalho e da produção}

Quando se trata dos problemas sociais vinculados ao jovem rural, é comum associar as formas de produção e trabalho na agricultura familiar. A evolução das políticas públicas enfatiza as relações produtivas como essenciais para a permanência e para a reprodução econômica da categoria, tomando como ponto de partida a carência de financiamentos, sendo, também, um dos pressupostos analisados pelo Estado para a continuidade no rural como, por exemplo, a linha específica do jovem no Pronaf. O enfático esforço, focado na intervenção estatal ligado apenas por anseios produtivos, ofusca as ambições dos jovens rurais, que vão além dos componentes trabalho e produção.

As políticas públicas fornecem uma variedade de oportunidades, como o acesso ao crédito, à terra e à infraestrutura, mas, talvez, não seja suficiente para alcançar o objetivo proposto, que é a permanência no rural. Assim sendo, eximem-se análises voltadas para a sociabilidade, as formas de lazer, o entretenimento e a cultura. Elementos que podem amenizar o isolamento do campo, nato do espaço rural, que é caracterizado por uma menor concentração, com distâncias acentuadas entre as propriedades.

A maioria dos jovens migra para centros urbanos, por anseios individuais, inclusive, é uma atitude controversa à concepção de que a saída representa a existência de uma família descapitalizada do campo. Ao contrário, em sucessivos casos, a renda na propriedade é elevada, proporcionando acesso a bens e serviços que, talvez, nas condições e possibilidades de trabalho urbanas, não alcançaria o patamar de igualdade.

A condição econômica das famílias, segundo Redin e Silveira (2012) envolvendo aspecto patrimonial e nível de renda, não está correlacionada com a opção por permanecer ou sair do rural. Pensar a manutenção no rural não significa mais apostar na preparação para atividades agrícolas, mas buscar no diálogo com a juventude rural quais necessidades e expectativas de formação são mais coerentes com suas perspectivas de vida. Dito isto, fica claro que em cada região haverá propostas formativas mais adequadas a realidade da juventude rural, não havendo espaço para estratégias genéricas e amplas que busquem atingir qualquer rural. Trata-se de pensar a formação para a juventude a partir de suas expectativas e não de pressupostos que os agentes externos tenham sobre o que seria adequado para os jovens rurais.

Partilham expectativas positivas no urbano, buscam melhorar de vida e, em certos casos, também se desvinculam da terra por não gerar uma renda satisfatória pelo seu trabalho, conjugado as dificuldades de acesso viário, os problemas agrícolas e estruturais, as informações e o distanciamento do estilo requerido de ocidentalização do mundo. Por outro 
lado, também é importante destacar que, em certas regiões rurais, os jovens já têm acesso à internet via rádio, o que facilitou suas vidas, ou aproximou-os dos espaços sociais. No entanto, em certa medida, esse processo pode atribuir uma vontade intrínseca de sair do rural, pela percepção fascinante e idealizada do urbano. As diferenças de estilo de vida e as aparentes desigualdades entre o rural e urbano provocam uma insatisfação dos jovens rurais com as pertinentes desigualdades visualizadas, sempre em uma comparação com aqueles de classe média a alta, quase nunca fazendo analogia aos jovens periurbanos.

Em pesquisa no interior de Arroio do Tigre, Redin (2011) observou várias famílias com um, dois ou mais celulares, bem como, em menor expressão (mas já bastante visível), computadores, internet via rádio e televisões a cabo. Agricultores com acesso a informações em tempo real, sobre o comportamento do clima durante a semana, sobre as projeções para a safra, sobre o comportamento do mercado agropecuário, do dólar, ou a informações ligadas ao lazer e ao entretenimento. Em muitos casos, a motivação para os agricultores adquirirem computadores ligados à internet é explicada pelos seguintes elementos: a) pela presença de investidores privados na cidade de Arroio do Tigre, que visualizou oportunidade de mercado; b) pela existência de jovens, na propriedade, que necessitam elaborar trabalhos pelo computador, para fins de estudos no ensino médio, sendo muito custoso o deslocamento destes à cidade; ou, talvez o mais importante, c) o agricultor adquire a tecnologia e os serviços de internet com o objetivo de motivar a permanência do jovem rural na propriedade. Esse último elemento é um fator extremamente relevante, uma vez que os jovens são os únicos que sabem manusear o equipamento, sendo que alguns agricultores aprendem com os filhos. Ao mesmo tempo, esse processo acelera a inclusão digital dos agricultores.
Por outro lado, Redin (2011) explica que apenas os agricultores mais consolidados possuem os equipamentos, uma vez que aumentam, gradualmente, os custos com serviços externos à propriedade pela necessidade de quitamento da prestação mensal da internet . Nesse contexto, somente tem acesso aqueles que estão localizados em áreas mais privilegiadas, onde o sinal de internet não apresenta interrupções, pois a empresa responsável ainda não conseguiu difundir o sinal para todas as localidades de Arroio do Tigre, apesar de já ter expandido para outros municípios. Para os agricultores, o acesso à informação e aos serviços oferecidos pela internet é extremamente positivo para o desenvolvimento individual e da região. Nesse contexto, a migração também está ligada aos conflitos de interesses na família, pois entre os projetos dos jovens e a expectativa dos pais existe uma enorme lacuna. Brumer (2006) identificou nos jovens filhos de agricultores familiares no sul do Brasil, dois aspectos decisivos e conflitantes na família: a) o acesso a uma renda própria, cujos recursos eles possam decidir como utilizar e b) a sua autonomia em relação aos pais. Para a autora, o primeiro é dificilmente equacionável dentro da economia familiar, cujos recursos comumente são indivisíveis e ficam sob o controle do pai, e, para o segundo, são necessárias mudanças nas relações familiares, a fim de proporcionar maior espaço para atuação dos jovens.

Grosso modo, a sucessão da terra ficará com o herdeiro que demonstrar interesse em continuar com o trabalho no campo, o qual, muitas vezes, é aquele que não deu continuidade aos estudos, pois os problemas como o difícil acesso, a distância da escola, a precariedade do transporte, a qualidade do ensino, o desinteresse e a desmotivação, a dissonância entre o aprendizado e a realidade local, a desigualdade e o estigma produzido pelos colegas, desmotivaram a prosseguir. 
Brumer questiona a sua suficiência para compreender os aspectos relacionados à sucessão. Diante do insaciável problema de pesquisa, esclarece:

(...) em lugar de procurar responder à questão 'por que os jovens saem do meio rural' busque-se responder à questão 'por que os jovens permanecem no meio rural'. A formulação desta questão implica o conhecimento efetivo de instalação dos jovens, em atividades agrícolas ou não agrícolas, assim como das condições de vida e trabalho no meio rural. Implica também a análise das representações dos jovens com base na realidade (BRUMER, 2007, p. 50).

A continuidade da agricultura familiar, como se referem Brumer et al., (2005), está ligada à disposição dos jovens filhos dos agricultores em sucederem seus pais. Consequentemente, a não sucessão e o processo de êxodo dos jovens para os centros urbanos são percalços para o desenvolvimento da agricultura familiar. Talvez, a compreensão de Carneiro (1999) explique, em parte, o desinteresse pela sucessão, quando afirma que o meio rural é um espaço heterogêneo, diversificado e também agrega atividades não agrícolas, sendo que a juventude rural é a faixa demográfica mais afetada pela dinâmica das perdas de fronteiras entre o rural e o urbano. Isso faz com que o jovem rural almeje uma condição de vida urbana, o que está o atraindo por diferentes motivos: a) acesso à educação mais qualificada em universidades; b) oportunidade de trabalho proporcionando sua própria renda; c) lazer mais acessível, entre tantos outros. Tais elementos condicionam expectativas individuais, próprias e diferenciadas.
A falta de perspectivas no rural condiciona também jovens com menor qualificação a arriscar a vida nas cidades metropolitanas. Alguns retornam por não se adaptarem ao ritmo e ao estilo de vida urbano, outros continuam, mas, devido à pouca qualificação, sofrem restrições significativas para conquistarem um emprego valorizado e bem remunerado.

Em Arroio do Tigre, a maior parcela de jovens rurais que migra para outras regiões tem por projeto de vida a formação superior. Dependendo das condições estruturais e financeiras da família, alguns retornam após a faculdade, outros seguem a vida fora da região, almejando crescimento profissional fora da propriedade rural. A predominância de culturas como a do fumo, integrado a indústria do tabaco, bem como outras atividades não-agrícolas, facilitam o processo de retorno, pela possibilidade de boas condições de renda. Mas, nem sempre, essa hipótese torna-se o principal fator de decisão.

Os jovens rurais têm sonhos, expectativas e ambições. Essas simbologias estão ligadas aos projetos de vida do jovem rural, dependendo, além dos espaços sociais, das condições vinculadas à propriedade. Famílias consolidadas economicamente podem proporcionar uma estrutura educacional que, talvez, induza o jovem a migrar parcialmente, com intuito de qualificação superior. Caso o indivíduo opte por cursos na área agrícola, quem sabe, a possibilidade de retornar seja mais elevada. Geralmente, as moças do meio rural optam por cursos desvinculados das ciências rurais, por uma série de motivos ligados a penosidade do trabalho rural e também pelo status sobre cursos considerados urbanos.

\footnotetext{
${ }^{2}$ A mensalidade para a transmissão do sinal em 2010 chega ao patamar de $R \$ 50,00$ para a prestação do serviço

${ }^{3}$ A importância da cultura do fumo nas propriedades rurais é discutida em Redin (2010) sobre um estudo de caso em Jaguari/RS. Consultar: REDIN, E Fumicultura e agricultura familiar: o caso de Jaguari/RS. Revista Sociais e Humanas. v. 23, n. 02, jul/dez 2010, p. 99-116. Ou ainda pesquisa sobre o município de Arroio do Tigre/RS, maior produtor sul-brasileiro de fumo tipo Burley. Ver Redin (2011).
} 
De outro lado, encontram-se as famílias com menores condições econômicas, pelo que limitam, em parte, a possibilidade de perspectivas maiores antes de suprir as condições fisiológicas. Nesse sentido, os indivíduos têm limitações estruturais e psicológicas, no entanto, sonhos, perspectivas e desejos ilimitados. A autoconfiança aumenta ou diminui de acordo com a estrutura familiar e com outros condicionantes, como apoio de políticas sociais.

O Programa Universidade para Todos (Prouni), por exemplo, fortaleceu o sonho de o jovem rural cursar ensino superior em universidades particulares, aliado também aos incentivos do programa de expansão do ensino superior público no país. $\mathrm{O}$ Prouni possibilitou aos jovens investirem em ensino superior, sem a necessidade de migrar para regiões tão distantes, vinculado a meritocracia individual (dependendo da capacidade intelectual, obviamente). Nesse sentido, há alguns casos em Arroio do Tigre, jovens rurais vinculados ao Prouni tiveram a oportunidade de estudar sem necessitar sair permanentemente da propriedade. No entanto, isso não é uniforme em todos os cenários e regiões. Apesar dessas possibilidades, grande parte dos jovens que permanecem no rural acaba desistindo dos estudos ainda no ensino fundamental, simplesmente, por não perceber, na escola, aprendizados que atraem sua atenção, ou por sentir desestímulo individual próprio. Outra limitação presente é a oferta de cursos ligados, especialmente, a áreas urbanas, não atendendo os anseios daqueles que optam por vincular o aprendizado superior as atividades voltadas para a área agrícola. Existe, portanto, uma limitação estrutural também das próprias universidades particulares.

Redin (2010) elenca vários fatores da possível saída do jovem do campo: a) um parceiro para manter vida social; b) a educação superior; c) a autonomia financeira, desvinculada do chefe da família (pai); d) a busca de lazer e de entretenimento propiciada nos meios urbanos; e) o status midiatizado do jovem urbano; e f) a possibilidade de buscar oportunidades de crescimento pessoal. Nesse sentido, também se torna interessante evitar as dificuldades do meio rural como: g) as precárias condições de trabalho; $h$ ) a dificuldade de acesso ao meio urbano; i) o isolamento cultural, social e político no meio rural; $j$ ) falta de uma estrutura de apoio; 1) a inexistência de acesso às tecnologias de informação da sociedade urbana no campo (sinal de celular e de internet, etc.), entre outros. Subsidiar e oferecer apoio a condições de acesso à educação, a oportunidades de lazer e a espaços socioculturais ao jovem rural são premissas básicas para que exista a possibilidade de escolha dos indivíduos e, desse modo, prospectar relações vitais, as quais valorizem o convívio na comunidade, no trabalho, na produção, na natureza e nas diferentes interações entre a sociedade. Talvez, a partir disso, prospectar cenários e expectativas positivas no rural, ultrapassando a visão restrita de que os jovens rurais pensam apenas em melhores condições de trabalho e produção, instaurada no cerne das políticas agrícolas. É necessário transpor a concepção da categoria como um problema social, analisando-os como protagonistas do desenvolvimento rural.

\section{Um caso atípico: a Associação da Juventude Rural de Arroio do Tigre - AJURATI}

A juventude rural ainda caminha no sentido de buscar espaço na sociedade, principalmente, nas regiões rurais brasileiras. Marin (2009) defende a tese de que a juventude rural é uma invenção da sociedade industrial, emergindo com a modernização da agricultura, processo que instituiu a categoria 
nos discursos e nas práticas das instituições de desenvolvimento. Mas isso não significa que, antes da industrialização, não existia jovens rurais, porém que a juventude, nas sociedades camponesas, não integrava uma fase distinta e definida do ciclo de vida dos indivíduos, completa o analista.

A extensão rural, vista como mecanismo promotor de difusão de inovações e tecnologias para o rural, após a metade do século XX, trabalhou com diferentes formas e métodos para qualificar os atores rurais em busca do referido desenvolvimento da época. Uma das instituições responsáveis pelo trabalho, no Rio Grande do Sul, ficou a cargo da Empresa de Assistência Técnica e Extensão Rural (EMATER), juntamente com a Associação Sulina de Crédito e Assistência Rural (ASCAR). O programa de Clube 4-S (saber, sentir, saúde e servir) foi inserido como uma das maneiras de facilitar, agilizar e dar eficácia a transmissão do conhecimento para o rural, usando os jovens rurais como agentes interlocutores entre o extensionista e o agricultor. A partir disso, a preocupação com o gênero ganha destaque, talvez, pela expressiva necessidade de alcançar resultados significativos em relação à produtividade de alimentos, na época.

A empresa de assistência técnica instala-se em 1978, em Arroio do Tigre/RS, sendo que, no ano seguinte, é desenvolvido o programa em quatro localidades: Linha São Pedro, Sítio Alto, Linha São Luís (atual, município de Estrela Velha) e Vila Progresso. A base inicial foi reunir grupos de jovens para difundir conhecimentos técnicos sobre alguma atividade agrícola. Nesse caso, lavouras demonstrativas de milho, a fim de modificar o cenário produtivo tradicional, considerado como atrasado para o desenvolvimento da época. A tarefa, posterior era que cada jovem implementasse uma lavoura similar em sua propriedade. Os resultados dessa ação converteram-se em aumento de produtividade do grão nas unidades agrícolas, agradando aos agricultores. Além das atividades práticas, eram realizados encontros mensais com os grupos.

A experiência teve êxito; no entanto, o estímulo dos jovens rurais ultrapassava a concepção do trabalho, reivindicando algo além do ensino de técnicas agrícolas. O marco dessa iniciativa aconteceu quando os grupos questionaram as ações voltadas apenas para o trabalho. Após construção e planejamento dos técnicos locais, sugeriu-se criar um espaço de lazer, educação e entretenimento, sendo isso dialogado com os jovens. A ideia mobilizou outras localidades que até o momento não participavam dos grupos, como Linha Cereja, Itaúba (hoje, Estrela Velha), onde se formaram mais duas iniciativas. Em agosto de 1983, foi sugerida a criação do Dia do Jovem no ginásio e no salão da paróquia católica. Esse evento ficou marcado na história como a $1^{\circ}$ olimpíada rural, que contou com a participação de nove grupos (compostos de 40 integrantes cada), integrando palestra de abertura e diferentes modalidades esportivas disputadas (modalidades futsal masculino, voleibol masculino, voleibol feminino, prova rústica masculina e prova rústica feminina). No encerramento do encontro, foi escolhida a rainha entre os participantes. $\mathrm{O}$ evento - pioneiro no Estado do Rio Grande do Sul - proporcionou um dos maiores bailes da região, trazendo expectativas, mobilização dos atores sociais, e motivando a comunidade, principalmente, rural.

A segunda edição das olimpíadas rurais, no ano seguinte, contou com a participação de doze grupos, sendo ampliada para dois dias, agregando outras modalidades esportivas, como

\footnotetext{
${ }^{4}$ Segundo a Associação Brasileira de Crédito e Assistência Rural (ABCAR), os Clubes 4-S eram grupos de jovens rurais com idade entre 10 a 21 anos, organizados com ação educativa, orientados por líderes desenvolvendo trabalhos individuais com a finalidade econômica e social, com vistas a promover o desenvolvimento.
} 
o bolão. A participação dos grupos era autogerida pelos extensionistas da empresa, sendo que as comunidades interessadas procuravam e informavam-se do evento e das condições estabelecidas e, aos poucos, as olimpíadas rurais consolidaram e incorporaram a tradição local, segundo Redin et al., (2009).

Em 1989, foi criado o Conselho Municipal da Juventude Rural de Arroio do Tigre, que proporcionou a democratização das decisões e a participação efetiva dos jovens rurais na organização do evento (REDIN, et al., 2009). O intercambio social foi um dos pontos positivos diante dos jovens rurais das comunidades. Cada comunidade foi denominada, posteriormente, de juventude rural, tendo um líder legitimado (jovem rural) que a representava nas deliberações coletivas. A formação de lideranças de jovens rurais constituiu-se em um dos objetivos do projeto local. Essa interação social entre os jovens da comunidade rompeu os limites territoriais, sendo que, anteriormente, as moças e os rapazes estabeleciam matrimônio na própria localidade. Após essa iniciativa, os jovens começaram a constituir família com pessoas de outros locais, no município.

Em 1996, na $12^{\circ}$ edição do evento, estimulados pelos gestores públicos estaduais, no dia dezoito de Maio, foi criada a Associação da Juventude Rural de Arroio do Tigre, como instituição legal, possibilitando o repasse de recursos para organização de eventos e atividades sociais, culturais, etc. O estatuto da associação identifica sua finalidade: “(...) uma entidade educacional, filantrópica, esportiva e recreativa, sem fins lucrativos e tem como finalidade principal coordenar os Grupos de Jovens Rurais do Município de Arroio do Tigre, usando a sigla de AJURATI"
(1996, p. 2). Conforme expressa Redin et al., (2009), a formação da associação fornece competência para os jovens rurais, além da organização do evento, construindo um espaço simbólico que valoriza as origens, representando, na figura da AJURATI, todos os grupos (juventudes) existentes no interior do município. A administração é realizada pelos jovens, sem ganhos financeiros, exercendo, principalmente, as seguintes funções e deliberações:

I - Representar os Grupos de Jovens Rurais do Município de Arroio do Tigre, no Município ou fora deste; II - Coordenar as ações desenvolvidas pelos Grupos de Jovens filiados; III- Incentivar a fundação de Grupos de Jovens Rurais dentro da área do Município de Arroio do Tigre; IVInterpretar e estabelecer as normas e diretrizes do trabalho, promoções e atividades em geral dos Grupos filiados; V- Pleitear e receber recursos para desenvolver seus projetos, dando lhes a destinação; VI - Desenvolver atividades, em consonância com seus objetivos fundamentais; VII- Elaborar o programa anual de atividades, de acordo com as necessidades de cada Grupo e de acordo com os interesses locais (ESTA-TUTO DA AJURATI, 1996, p. 5).

A associação passa a exercer influência nas deliberações e nas novas formações de grupos de jovens no interior do município, através de suas competências estatutárias. $\mathrm{O}$ capítulo II do estatuto refere-se à formação dos grupos de jovens rurais: "Artigo $3^{\circ}$ Os Grupos de Jovens Rurais poderão ser fundados nas diversas localidades do Município de Arroio do Tigre e sua filiação junto à AJURATI ficará condicionada aos seguintes requisitos: I - Ata de fundação, com pelo menos,

\footnotetext{
5 A Associação da Juventude Rural de Arroio do Tigre (AJURATI) possui vinte grupos de jovens rurais, denominados juventudes onde representa, coordena, desenvolve atividades e elabora programações anuais das juventudes rurais associadas. Administrada somente por jovens rurais que integram as vinte juventudes, a presidênciá mantida sem pagamentos de hońrios. A AUURATI comó órão maior é a responsável pelo cumprimento de seu estatuto pelas juventudes associadas, bem como rege todas as regras definidas pelos seus associados, ou seja, todos os jovens rurais representados pela presidência de cada juventude, na ocasião de definição de estratégias.
} 
dez jovens rurais filiados ao Grupo; II - Requerimento de filiação; III- Nominata da Diretoria eleita" (1996, p. 5). Após os procedimentos, encaminha-se o protocolo para a Associação que: "Artigo 4- Recebido o pedido de filiação, a Diretoria da AJURATI o julgará; Parágrafo $1^{\circ}$ - O Presidente de cada Grupo de Jovens Rurais, automaticamente, integrará a Diretoria da AJURATI, na condição de Conselheiro; Parágrafo $2^{\circ}$ - Os sócios dos Grupos filiados, automaticamente, serão considerados sócios da AJURATI" (1996, p. 5-6).

A existência de procedimentos formais, com direitos, deveres e possíveis penalidades aos integrantes e/ou grupos que não seguirem as exigências do estatuto, organiza, de certa maneira, os jovens, evitando conflitos posteriores, processo que motivou os integrantes. A organização, a união, a cooperação, a integração e os vínculos de amizade, elementos subjetivos no processo, tornaram-se essenciais diante da associação, uma vez que pode-se consolidar um importante espaço de valorização e de reconhecimento social. Nesse processo, surgiram lideranças importantes, como Presidente da Cooperativa Agrícola Mista Linha Cereja LTDA (COMACEL) e do Sindicato dos Trabalhadores Rurais (STR). Outros jovens rurais são vereadores do município, integrantes dos principais segmentos da sociedade local (REDIN, et. al., 2009).

A décima quinta edição marcou-se pela ampla divulgação a nível estadual, incentivando outros municípios da Região Centro-Serra a organizarem as olimpíadas rurais. Em 1998, o município sediou os IV Jogos Rurais do Rio Grande do Sul e os III do CONESUL. Foram 42 delegações de jovens vindos de diversas partes do Estado e uma do Uruguai. Aproximadamente, oitocentas propriedades rurais do município abrigaram cerca de 2000 jovens rurais. Em 2002, Arroio do Tigre vol- tou a sediar esse evento (REDIN, et al., (2009); RAUBER, et al., 2008). A entidade construída, após um processo de intervenção produtiva, tomou outro rumo. A readaptação do projeto original do Clubes 4-S para espaços de lazer, cultura e entretenimento intermediou uma construção social conjunta entre técnicos e jovens rurais, que marcou formas de participação e de integração social locais. De viés similar ao de Bourdieu, a AJURATI (1996, p. 6) delimitou sua concepção de jovens rurais: "Definem-se como Jovens Rurais, todos aqueles que sejam filhos de agricultores e que se dediquem às atividades rurais, ou se estiverem ligados à atividade agrícola, residindo no meio rural".

O reconhecimento da organização dos jovens promoveu estímulo dos gestores públicos municipais no lócus das ações públicas de incentivos estruturais. Um exemplo concreto desse fato é a construção, através da Prefeitura Municipal, de quadras esportivas em todas as comunidades onde existem grupos de jovens. $\mathrm{O}$ evento, realizado no final de abril, culminando o fechamento no dia $1^{\circ}$ de maio (dia do trabalhador), integra, atualmente, 20 grupos de juventudes rurais, que, durante quatro dias, disputam diversas modalidades de esportes nos espaços urbanos do município. A data para realização do evento é intencional, uma vez que possibilita à sociedade urbana prestigiá-los em um momento singular do ano.

Por outro lado, a olimpíada rural não se resume apenas a quatro dias de evento no centro urbano, pelo contrário, as atividades preparatórias mobilizam os jovens durante todo o ano, intervalo no qual cada juventude rural (leia-se grupo de jovens) promove um evento em um domingo do mês, com competições na sua localidade, principalmente, o futebol masculino e a disputa de pênaltis. Ao final, encerra-se com uma domingueira conduzida por um grupo musical de relevância local, ou mesmo de outra região. A participação dos jovens é regulamen- 
tada pelo estatuto definido pela AJURATI e pelos seus associados. É necessário que todos os vinte grupos de jovens envolvam-se nas atividades das comunidades rurais do município, para legitimar a participação nas sobras financeiras provenientes do evento maior, que é a olimpíada rural no mês de maio. Entretanto, nos eventos que acontecem no interior, não se limita a participação de jovens urbanos e nem de grupos de outros municípios, pois é de interesse da juventude rural em questão que seu evento repercuta e oportunize sobras para manter os custos anuais da participação da sua juventude no evento das outras. Portanto, existe um processo de cooperação e de ajuda mútua entre os grupos, com a finalidade de movimentar e fornecer validade ao movimento de valorização da categoria, bem como de oportunizar espaços de entretenimento e diversão no meio rural.

A organização das juventudes rurais ligadas a AJURATI é tamanha, que envolve os jovens o ano todo, com os chamados treinos, ou seja, durante um dia da semana, os integrantes das juventudes rurais, de sua respectiva localidade, se reúnem à noite para a prática de esportes, tanto na modalidade feminina como masculina, com intuito de aperfeiçoar suas técnicas a fim de disputar a olimpíada rural. A juventude que alcançar o maior número de vitórias, bem como a que for a mais organizada e disciplinada leva o título de campeão da "Olimpíada Rural de Arroio do Tigre", o que garante um status ao grupo perante a sociedade e as empresas da região, diante da necessidade de buscar recursos para confeccionar camisetas, fazer viagens, eventos e outras atividades.

No fechamento do evento, é organizado um baile com a escolha das rainhas e princesas que terão a função de representar a AJURATI nos eventos sociais promovidos no município, ou fora dele. A escolha das soberanas (jovens rurais) acontece em duas etapas: a) a primeira é realizada uma entrevista sobre conhecimentos gerais, abordando temas relativos à história da AJURATI e das juventudes rurais a ela ligadas, bem como a assuntos atinentes à importância da agricultura familiar na região e a outros afins; b) o segundo momento é o desfile das candidatas no evento, sendo avaliadas pela comissão julgadora, com apoio e estímulo das torcidas organizadas pelos jovens rurais. A olimpíada rural de Arroio do Tigre é considerada o maior evento do gênero do Estado do Rio Grande do Sul e já teve a presença de deputados, governadores e senadores da república, entre outras lideranças.

Além de atividades de lazer, a Associação promove cursos, palestras, eventos culturais, exigindo das juventudes rurais a presença de um percentual de jovens de cada grupo, como forma de envolvê-los nas atividades. Caso as juventudes não atinjam o percentual de integrantes combinado, a AJURATI, com seus associados (todas as juventudes rurais), define um percentual menor de participação nas sobras financeiras advindas da olimpíada rural para aqueles que descumpriram o acordo estabelecido previamente. Um dos eventos constitui-se na Jornada de Trabalho, realizada sempre, após o mês de maio, com um dia de palestras e de atividades para os jovens rurais. Na XI Jornada de Trabalho de Arroio do Tigre, em 2009, houve a presença de palestrantes como José Antônio Costabeber e Rosani Spanevello .

A AJURATI também participa de reuniões regionais, incluindo grupos de jovens de outros municípios, formando a Associação Regional da Juventude Rural (AREJUR). Em julho de 2011, aconteceu o encontro regional de jovens, em Passa Sete/RS, com a finalidade de discutir a sucessão familiar e a diversificação da produção. Nesse seminário, foram abordadas as políticas públicas para a agricultura familiar, com a representante da Secretaria da Agricultura Familiar (SAF) do Ministério do Desenvolvimento Agrário (MDA), Christianne Belinzoni, e com o diretor adjunto do 
Departamento de Agricultura Familiar da Secretaria de Desenvolvimento Rural, Pesca e Cooperativismo (SDR), Armando Enderle. Belinzoni, auxiliando Adriana Gregolin (coordenadora do projeto de diversificação em áreas cultivadas com tabaco), palestrou sobre as políticas da SAF que podem ser integradas para a diversificação das atividades produtivas, o contexto do programa, os objetivos e as alternativas de diversificação. Geralmente, os eventos são realizados em parceria com a EMATER e integram também palestras dos extensionistas da empresa.

A XIII jornada do trabalho, promovida no final de julho de $2011 \mathrm{em}$ conjunto com a EMATER local, abordou uma discussão sobre as prioridades da região, com a finalidade de enviar as demandas para o Estado. O momento serviu de base para reflexão em torno das atividades de diversificação e das perspectivas dos jovens rurais. Nesse encontro, foram eleitos quatro jovens rurais para representar o município na regional de Porto Alegre/RS.

O lema da AJURATI: "O jovem rural conquistando o seu espaço", parece traduzir, em certa medida, o esforço longitudinal de jovens rurais que, ao longo do tempo, abandonaram a invisibilidade construída para se tornarem, talvez, protagonistas de experiências positivas, atualmente, sendo objeto de análise e de reflexão. A associação serviu de exemplo para a constituição da Associação da Juventude Rural de Sobradinho (AJURS), da Associação da Juventude Rural de Estrela Velha (AJUREV), da Associação Municipal de Juventude Rural de Segredo (AMJURS), da Associação da Juventude Rural de Lagoa Bonita do Sul (AJURLABS), da Associação Municipal de Juventude Rural de Passa Sete (AMJURPS), da Associação Municipal da Juventude Rural de Ibarama (AJURI), da Associação Candelariense da Juventude Rural (ACAJUR), da Associação de Juventude Rural de Lagoão (AJURAL), da Associação de Juventude Rural de Cerro Branco (AJURCEB), da Associação da Juventude Rural de Agudo (AJURA), do Conselho Municipal da Juventude de Tunas (COMJUT), do Conselho Municipal de Juventude Rural de Salto do Jacuí (CODEJURS), entre outras, totalizando 17 organizações municipais que formam - por assim dizer - o ente maior, denominado de Associação Regional de Juventude Rural (AREJUR).

O reconhecimento é tamanho, que os jovens urbanos de Arroio do Tigre iniciaram, há três anos, a organização de um evento similar, inclusive, com regras que coordenam as atividades, denominado de "Olimpíada do Comércio". O espaço organiza jovens (sem limitação de idade) que trabalham nas empresas locais, representando-as no evento. A quarta edição aconteceu no mês de novembro de 2011, próximo às festividades de aniversário do município.

A consistência dos grupos de jovens rurais no município, também influencia em datas festivas de outras associações ou de outros grupos existentes nas comunidades rurais. A associação dos jovens conseguiu constituir uma identidade própria diante de relações estimuladas, a partir de diferentes práticas, valores, crenças e atitudes, coletivamente representadas pelos vínculos estabelecidos entre eles e com a sociedade local.

Nas atividades esportivas, no lazer, na educação e no entretenimento que envolvem os jovens rurais do município, é possível de se constatar o orgulho, o prazer e a motivação de serem identificados como jovens rurais.

\footnotetext{
${ }^{6}$ José Antônio Costabeber na época era extensionista da Emater/RS. No mesmo ano integra o quadro de docentes e pesquisadores do Departamento de Educação Agrícola e Extensão Rural da Universidade Federal de Santa Maria.

${ }^{7}$ Rosani Spanevello é docente e pesquisadora da Universidade Federal de Santa Maria, vinculado ao Centro de Educação Superior Norte-RS (CESNORS).

${ }_{8}^{8}$ Para uma discussão sobre agricultura familiar fumageira de Arroio do Tigre, consulte: REDIN, E. Entre o produzir e o reproduzir na agricultura familiar fumageira de Arroio do Tigre/RS. (Dissertação de Mestrado). Santa Maria: PPGExR/UFSM, 2011.
} 
Nas entrevistas realizadas, em trabalho anterior (REDIN et al., 2009), pode-se constatar várias falas que traduziam formas de autoidentificação, como: orgulho, gostar do que faz, participar das olimpíadas, ser unido, entre outras simbologias que foram destaque. Esses elementos de caráter simbólico surgiram pelo fato de a entrevista ser realizada no auge da Olimpíada Rural e, talvez, teriam dimensões diferentes quando interrogados em trabalho cotidiano, na propriedade. No entanto, nessa reflexão, é possível identificar a importância da AJURATI para os jovens rurais, que se mobilizam, semanalmente, com tal propósito. É uma associação que conseguiu reconhecimento e legitimidade pela sociedade local, mobilizando outros territórios a constituir uma juventude rural organizada.

A associação insere-se como uma entidade organizada importante para estímulo, valorização e legitimidade do jovem rural no local, sendo que, em certas circunstâncias, pode ser relevante instrumento motivador para a permanência no rural; mas inferir que ela evite a migração seria arriscado demais. Os jovens rurais, que fortalecem a preferência pelo interior, fazem considerações sobre tranquilidade, liberdade (tanto de horários, como de subordinação a chefes), motivação, liderança, vínculos de amizade e integração dos jovens, como fatores preponderantes sobre o urbano.

O trabalho da associação conduz os jovens a manterem vínculos com o rural, como aponta o trabalho de Redin et al., (2009, p.126), na citação de um entrevistado, comentando sobre a AJURATI: "Influencia porque só participa dela quem é do interior. Cursos, palestras e dias de campo que a AJURATI proporciona. Ela influencia a ser do meio rural". Nesse momento, através de afirmações e depoimentos de diversos integrantes, consolidaram-se elementos favoráveis à organização como instrumento facilitador e motivador para a permanência no rural, talvez, pela exclusividade da participação de jovens rurais no evento, sendo um privilégio perante a sociedade local e perante os jovens urbanos. Também, como já se salientou, a inexistência de ensino técnico e superior público no município faz com que muitos jovens, apesar da existência da AJURATI, tenham que mudar de município para conseguir dar continuidade aos estudos.

A associação já registrou casos em que jovens abandonaram as atividades agrícolas para trabalhar na cidade local, mas a insatisfação com o trabalho e com a remuneração, a não adaptação ao estilo de vida e a necessidade de voltar às atividades dos grupos, conduziu jovens a retornarem para o campo, reativando suas origens e regressando às atividades das juventudes rurais. A AJURATI e os grupos de jovens rurais alcançaram importantes graus de sociabilidade, reconhecimento, laços de confiança e respeito na comunidade, ao longo do tempo.

Nesse sentido, o caso da organização revigora que as políticas não podem ter objetivos voltados apenas para a produção e para o trabalho, mas também para fortalecer outros espaços importantes para a formação de cidadania e protagonismo dos jovens rurais. A construção social, estimulada pelo grupo 4-S, reverteu-se em importante espaço de convivência, de troca de experiências, de formas de lazer e entretenimento e em uma entidade legitimada pelas sociedades local e regional. Essa experiência local vem corroborar a evolução associativa da organização social, enquanto agente transformador que, talvez, contemple formas de atuação frente à necessidade expressiva de assegurar propostas que estimulem o jovem a permanecer no campo.

\section{Considerações finais}

A temática é instigante, e os fios condutores dessa análise proporcionam 
diversas interpretações. A dinâmica, no rural, é difícil de ser generalizada, tanto quanto as indecisões, as ambiguidades e as formas contraditórias de compreensão de mundo do jovem rural em questão. O questionamento "por que os jovens migram?", talvez, nunca seja respondido de forma completa, sem estar embasado em uma experiência, seja ela positiva ou não. Quando permanecem no campo, podem estar atrelados a fatores que nem sempre são motivadores ou estão ligados a projetos de vida escolhidos, mas perante limitações de opções ou de projetos de vida forçados. Esse laboratório de observação antagônico é rico, no momento, que pese as diversas características que compõem uma experiência.

A AJURATI, como associação derivada de um projeto voltado especificamente para a produção, torna-se eixo central de orientação social, lazer e entretenimento para a juventude rural, no município. $\mathrm{O}$ espaço social criado e incentivado possibilita que os jovens interajam com a sociedade de forma positiva, principalmente, através do esporte e da sua capacidade de organização local e regional. Ultrapassando-se a questão da organização, percebe-se, claramente, um desapontamento dos jovens quando se relaciona a perspectiva de reprodução de ciclo curto, ou seja, de desvalorização dos produtos agrícolas e do trabalho embutido nas atividades, talvez, requerendo uma atuação mais efetiva em políticas reguladoras do Estado. Por outro lado, fica claro que é necessário suplantar a concepção de políticas apenas voltadas para o trabalho e a produção, criando outros caminhos, fortalecendo e contemplando formas de organização, sociabilidade, educação e cultura no rural.

Por fim, o estudo ressalta a importância da organização dos jovens rurais para suplantar a invisibilidade e para implantar um reordenamento da percepção do jovem rural em questão, nas diferentes formas intervencionis- tas, com vistas ao desenvolvimento da categoria. Promover condições de inserção social, diante de atividades que acenem formas de motivação, reconhecimento, legitimação e contraste social é, sem dúvida, um processo essencial para equalizar as distorções promovidas pelos diferentes graus de oportunidades e pelas diferentes formas de acesso, que aludem à promoção da qualidade de vida no rural atualmente.

\section{Referências bibliográficas}

ABRAMOVAY, R. et al. Juventude e agricultura familiar: desafios dos novos padrões sucessórios. Brasília: UNESCO, 1998.

AJURATI. Estatuto da Associação da Juventude Rural de Arroio do Tigre. Arroio do Tigre: Registro de Imóveis, 1996.

BOURDIEU, P. Questions de sociologie. Paris. Éditions de Minuit, 1984.

BRUMER, A. A problemática dos jovens rurais na pós-modernidade. In: CARNEIRO, Maria José; CASTRO, Elisa Guaraná de. Juventude rural em perspectiva. Rio de Janeiro: Mauad X, 2007, p.35-51.

BRUMER, A. A problemática dos jovens rurais na pós-modernidade. In: Congresso Latino-Americano de Sociologia Rural, VII, 2006. Quito, Equador. Anais eletrônicos... Disponível em: < http://www.alasru.org/cdalasru2006/02\%20GT\%20Anita $\% 20$ Brumer.pdf $>$, Acesso em 23 de Jul. de 2011.

BRUMER, A.; PANDOLFO, C.G; CORADINI, L. Gênero e agricultura familiar: projetos de jovens filhos de agricultores familiares na Região Sul do Brasil. Fazendo Gênero 8 - Corpo, violência, poder. Florianópolis, 2005. 
BRUMER, A.; SPANEVELLO, R. M. Jovens agricultores da Região Sul do Brasil. Porto Alegre: UFRGS; Chapecó: Fetraf-Sul/CUT, 2008. Relatório de Pesquisa.

CAMARANO, A. A.; ABRAMOVAY, R. Êxodo Rural, Envelhecimento e Masculinização

CARNEIRO, M. J. Camponeses, agricultores e pluriatividade. Rio de Janeiro: Contra Capa Livraria, 1998.

CARNEIRO, M. J. O ideal rurbano: campo e cidade no imaginário de jovens rurais. In: F. C. TEIXEIRA DA SILVA et al. (orgs.), Mundo Rural e Política. Rio de Janeiro, Ed. Campus/Pronex, 1999.

CASSOL, A. L.. Êxodo Rural: Colonização e Ecologia. Porto Alegre: Martins Livreiro, 1984.

CASTRO, E. G. Entre ficar e sair: uma etnografia da construção da categoria jovem rural. (Tese de Doutorado). Rio de Janeiro: UFRRJ, 2005.

CASTRO, E. G. Juventude rural no Brasil: processos de exclusão e a construção de um ator político. Revista Latinoamericana de Ciencias Sociales, Niñez y Juventud [en línea], v.7, 2009. Disponível em: $<$ http://redalyc. uaemex.mx/src/inicio/ArtPdfRed. jsp? $\mathrm{iCve}=77307108>$. Acesso em 09 out. 2010.

DURSTON, J. A juventude rural no Brasil e no México: reduzindo a invisibilidade. Idéias \& debate. Brasília: Ins-tituto Teotônio Vilela, n. 27, 1999.

MARIN, J. O. B. Juventud rural: una invención del capitalismo industrial. Estudios Sociológicos, v. XXVII, 2009, p. 619-653. no Brasil: Panorama nos últimos 50 anos. 1997. Disponível em: $<$ http://www.ipea.gov.br/pub/td/td0621. pdf $>$. Acesso em 07 de Jul. de 2008.
PINHEIRO, A. C. A.; CARVALHO, M. L. S. Economia e Política Agrícolas. Edições Silabo, Lisboa-Portugal. 2003.

RAUBER, C. C. et al. Juventude Rural e Identidade as Olimpíadas Rurais em Arroio do Tigre-RS. In: $3^{\circ}$ Encontro da Rede de Estudos Rurais, 2008, Anais... Campina Grande. $3^{\circ}$ Encontro da Rede de Estudos Rurais, 2008.

REDIN, E.; SILVEIRA, P.R.C. Juventude rural: experiências e perspectivas. In: SANTOS, V. F.; VELA, H. A. G.; SILVEIRA, P.R.C. Educação rural no mundo contemporâneo. Vol. 1. 1. ed. Santa Maria: UFSM, 2012. p. 175-208.

REDIN, E. Entre o produzir e o reproduzir na agricultura familiar fumageira de Arroio do Tigre/RS. (Dissertação de Mestrado). Santa Maria: PPGExR/ UFSM, 2011.

REDIN, E. et al. O jovem rural, perspectivas e desafios no enfrentamento ao êxodo: o caso da Associação da Juventude Rural de Arroio do Tigre - AJURATI. In: Michele de Lavra Pinto; Janie K. Pacheco. (Org.). $2^{\circ}$ Encontro Juventude, Consumo \& Educação. Porto Alegre: Núcleo de Editoração e Criação Gráfica UFRGS, 2009, v. 2, p. 113-129. REDIN, E. O futuro incerto do jovem rural. In: $4^{\circ}$ Encontro Juventude, Consumo \& Educação, Anais... Porto Alegre: ESPM, 2010.

REDIN, E. O jovem rural conquistando o seu espaço: um [re]olhar sobre as questões sociais. Revista Brasileira de Agroecologia, v. 4, p. 2, 2009.

REUBEN, W. La juventud rural en América Latina y en el Caribe. San Jose: Instituto Interamericano de Cooperación para la Agricultura (IICA), 1990.

RODRÍGUEZ, E. Los desafios de fin de siglo y la problemática juve- 
nil rural en América Latina. 1993. CEPAL(Org.) Juventude Rural: Modernidad y democracia en América Latina. Santiago de Chile: Naciones Unidas, UNICEF e OIJ, 1996. p.33-54.

RUA, M. G. As políticas públicas e a juventude dos anos 90. In: Jovens acontecendo na trilha das políticas públicas. Brasília: CNPD, 1998.

SILVESTRO, M. et al. Os impasses sociais da sucessão hereditária na agricultura familiar. Florianópolis: EPAGRI; Brasília: NEAD, 2001

STROPASOLAS, V. L. O mundo rural no horizonte dos jovens. Florianópolis: UFSC, 2006. 